\title{
Using Multimedia Materials in the Teaching of Scientific and Technical Translation ${ }^{1}$
}

\author{
Juan Antonio Prieto Velasco, Maribel Tercedor Sánchez, Clara Inés \\ López Rodríguez \\ University of Granada
}

Information technology has changed the professional environment of scientific and technical translators, who must work with new formats and channels of information. To meet these new challenges, translation teachers must place special emphasis on the importance of the non-textual information evolving around multimedia texts and adopt a more dynamic approach towards audiovisual translation (AVT). In this paper, we argue for the inclusion of graphic information as a new focus for AVT, and present the results of a research project aimed at designing teaching materials for audiovisual, scientific and technical translation. These materials highlight the potential benefits of audiovisual resources for all users in the acquisition of subject field knowledge and terminology and the constraints imposed on translation by visual and acoustic material.

\section{New perspectives in audiovisual translation: new formats and channels of information}

In the same way as information technology has changed the competences of scientific and technical translators, it has also widened our perception of Audiovisual Translation (AVT), which is no longer limited to subtitling, dubbing and voice-over. Nowadays, AVT includes new formats and new channels of information, since, as Neves and Remael state (in this volume), "AVT is mingling with multimedia translation and localisation, channelling our access to information and entertainment that are today, more than ever linked".

Consequently, we argue for the inclusion of multimedia material in the audiovisual translation classroom (AVT) as a valuable means for students to become familiar with emerging forms of translation which highlight the knowledge of the subject field and its conventions, combined with some knowledge of audiovisual formats. The impact of the multimedia scenario has led to the appearance of the fields of audiovisual localisation and audiovisual accessibility as themes for recent conferences (i.e. Languages and the Media 2006; Audiovisual Media Accessibility for Disabled People 2006 and 2007) ${ }^{2}$.

This study has been carried out within a research project financed by the Andalusian Regional Government aimed at the generation of terminological resources within the domain of Integrated Coastal Management. The 
methodology and results of this project are also useful for the design of teaching materials in the context of Scientific, Technical Translation (Localisation), and Audiovisual Translation at university level (Tercedor \& Abadía 2005; López et al. fothcoming). Our students are third and fourth year undergraduate students working from English to Spanish and from Spanish to English in the BA in Translation and Interpreting of the University of Granada ${ }^{3}$.

Our pedagogical approach is social constructivism and collaborative learning (Kiraly 2000, González Davies 2004), which consider learning as a process of social interaction, "a view of society which has important implications for the way we guide students in developing the skills they will need as language mediators and full-fledged social agents" (Malena 2003). As opposed to the traditional translation classroom where knowledge would pass from the teacher to the students, in the collaborative classroom, the teacher acts as facilitator in the learning process, and the classroom is not separated from the real world. The translation brief is carried out under real-world conditions: there is a client and an expert in the subject field, and students work in groups and rotate their roles.

The first aim of this paper is to argue for the inclusion of multimedia contents as objects of study in AVT. We propose that AVT should be extended in the classroom to entail more than just film translation for subtitling or dubbing. Our second aim is to design multimedia teaching materials that will enable students to:

- $\quad$ assess potential internationalisation and localisation problems of a multimedia text in multiple subject fields;

- $\quad$ become acquainted with the tools available to manipulate multimedia objects and their use;

- $\quad$ increase their awareness of, and sensitivity to complex translational problems in multimedia scenarios;

- $\quad$ strengthen their skills to work in teams and cooperate with others;

- become aware of accessibility as a new requirement for web and multimedia contents.

Images, videos, animations, audio, etc. can be used in two different ways in the scientific and technical translation classroom: (a) as objects of translation (in localisation, dubbing, subtitling and audiodescription) or (b) as instructional resources when translating a scientific written text. 
2. Theoretical and methodological framework: dynamic images and text, knowledge representation and creative translations

The interaction of image and words in audiovisual material facilitates the comprehension and learning process, knowledge representation and the translation process, as shown in the following sections.

\subsection{A process-oriented Frame Semantics' approach to knowledge rep- resentation}

The research carried out under the MarcoCosta project revealed the multidimensionality and dynamism of the Coastal Management and Coastal Engineering domains on the base of a global representation developed in a previous R\&D project, the Coastal Engineering Event. This structure is based on dynamic conceptual macrocategories which entail becoming aware of the actions and the participants described in specialized texts (Faber, Márquez and Vega 2005).

Faber, Márquez and Vega (ibid.), in line with Barsalou (2003), claim that any representation of specialized knowledge must be dynamic and process-oriented with goal-derived categories that provide mappings from roles in action sequences to situated representations in real environments. These conceptual mappings will only occur in the minds of our students, if we conveniently exploit audiovisual material in the classroom. More specifically, we have to ask our students to manipulate the material (Asher $1982)^{4}$, to connect images to words, and to relate conceptual categories to their previous knowledge or some sort of general event, following a Frame Semantics perspective (Fillmore 1985).

The frame notion can be a means for grasping the meaning of the text and establishing links between concepts and specialized terms because a frame (Fillmore 1976) is a system of concepts interrelated in such a way that one concept evokes the entire system. Semantic networks are divided into domains, the domains into frames, and the frames into interrelated concepts. Therefore, we provide students with a conceptual frame representing the main processes involved in coastal engineering: the Coastal Engineering Event (Faber, Márquez \& Vega 2005).

\subsection{The role and functions of multimedia objects in knowledge repre- sentation}

An important issue regarding knowledge representation is the need to include information in other formats different from the most common verbal codification, in order to enhance textual comprehension. Despite its significant role in the transfer of information, the use of multimedia materials, especially pictorial elements, is still relatively infrequent in teaching environments, and occurs mostly in areas such as specialized knowledge intended for lay readers, (scientific journals like Nature and 
Scientific American) and in advanced scientific and technical contexts (Help files supported by flash animations or expert manuals describing laboratory apparatus).

The contiguity principle (Mayer \& Anderson 1992) proposes the extended use of graphic information which promotes interpretation processes in multimedia educational environments since the effectiveness of multimedia instruction increases when words and pictures are presented contiguously (rather than isolated from one another) in time or space.

The examples below belong to a scientific translation classroom and describe the different subprocesses composing RUNOFF. Example 1 exclusively deals with text to make the recipient understand key concepts, whereas Example 2 also offers an iconic image to denote the main concept RUNOFF. Knowledge transfer is much easier if the same information is represented at the same time in two different input formats: textual and graphic.

Table 1: Text with and without image

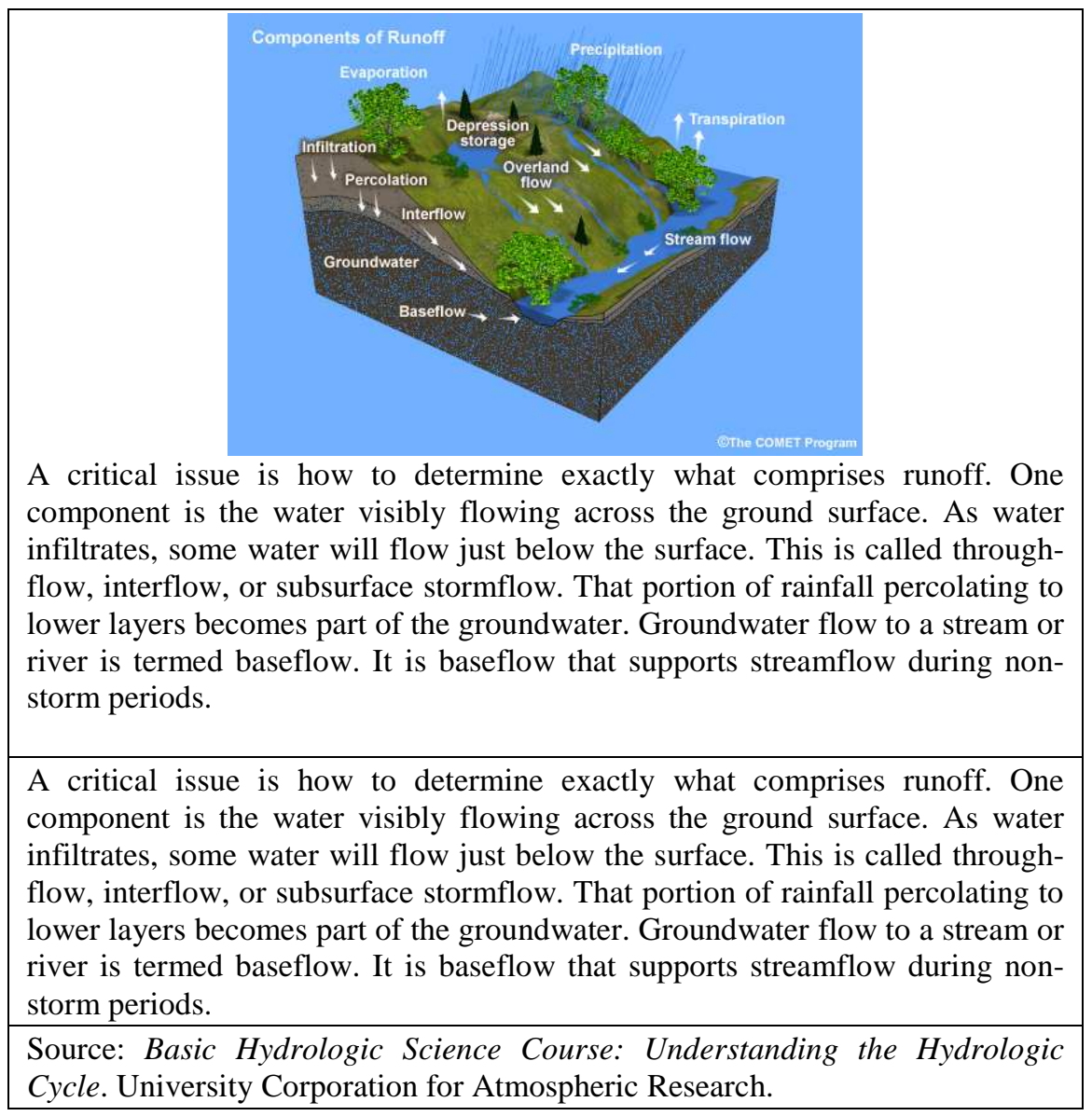


As suggested in the previous example, pictorial elements help to retain information in the working memory, to store it in the long-term memory and to recall conceptual relations for further categorisation and problemsolving processes (Parrish 1999). This is particularly relevant when both systems, verbal and pictorial, are presented as an interrelated whole. The principle of contiguity derives from the dual-coding theory (Paivio 1971; 1990), according to which information clusters are stored in the long-term memory both in the form of verbal propositions and of mental images. As a result, categorisation and the sub-processes involved (retention, storage, recall and eventually understanding) are easier when information appears in a doubly encoded interface containing linguistic and graphic representations.

Most research on dynamic images has used educational movies and concluded that animations involving movement and audio have very positive effects in the learning process, mainly when they are aimed at the representation of essential characteristics of a concept or its complex procedural nature (Anglin, Vaez \& Cunningham 2004; Faber et al. 2007).

In accordance with those theoretical principles, examples 1 and 2 highlight the use of graphic information in multimedia learning environments. In the first case, students can only extract information from text. However, in the second case, textual learning is supported by the dynamic pictorial representation of the conceptual relations among the subprocesses involved in RUNOFF. In this manner, students can reproduce a mental image of how the runoff process works in the real world and represent the dynamic configuration of the whole system of concepts. Therefore, the adequate management of graphic information plays a significant role in more creative translations, audiodescriptions and subtitles.

In this regard, Levin (1981) and Mayer and Gallini (1990) identified five prose learning functions in text-embedded images that can also be applied to the adequate management of dynamic elements in multimedia resources containing text, pictures and audio:

Table 2: Image functions and examples

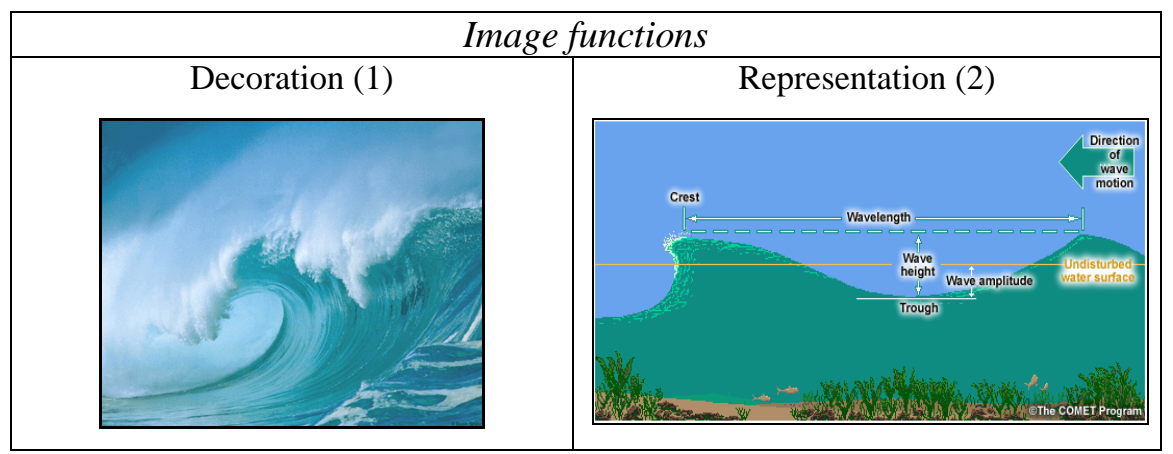




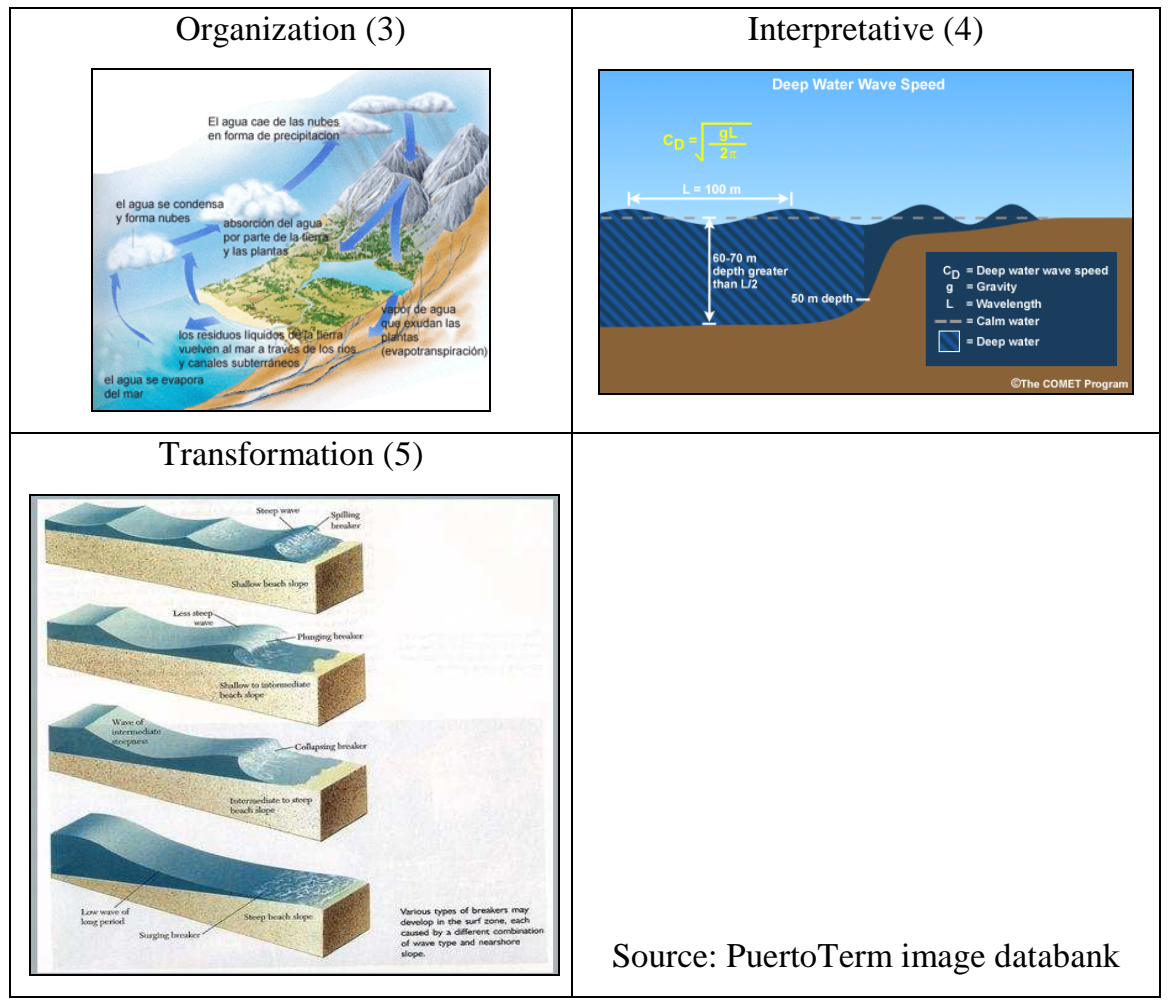

The decoration function is associated with images which are not relevant to the text but make it more attractive. Image 1 represents the concept WAVE but it does not add anything new to what it is verbally conveyed, except for an adornment. On the contrary, representational images are normally intended to convey the significant elements in the text. In this regard, Image 2 shows the most important concepts in the ANATOMY OF A WAVE and their interrelations, highlighting their verbal description. The organizational role contributes to create internal coherence and to build up an integrated structure. Image 3 represents the concept HYDROLOGIC CYCLE and describes the different stages which make up the whole process, creating a coherent unit jointly with the verbal explanation of the water cycle and its progression. Interpretative images enhance the clarification of passages and concepts difficult to understand. Image 4 shows the concept DEEP WATER WAVE SPEED by means of the representation of its mathematical traits in the form of symbols and the water depth in the form of iconic elements. The combined use of iconic and non-iconic pictorial elements reflects its conceptual complexity. The transformational function present in Image 5 is linked to special pictorial elements acting as a mnemonic technique. The representation of the different types of BREAKERS (surging, plunging, collapsing and spilling) is an aid to recall the information which depicts each type and the differences between them. 


\subsection{Visualization and creativity}

The new formats of scientific translation (that include more than ever audiovisual material in line with the notion of infotainment) have widened the scope both of scientific and audiovisual translation. Translators are now faced with new constraints (and possibilities) as well as with translation problems that demand increasingly creative solutions. And we believe that creativity is aroused in a collaborative classroom (Kiraly 2000) with authentic materials that combine images and texts.

Images and multimedia objects facilitate not only the learning process, but also the translation process. According to Kussmaul (2005), visualisations may lead to creative translations, in other words, translations that show changes when compared with the source text, thereby bringing in something that is novel.

Therefore, we ask students to describe and compare in the target language the visual material provided in order to facilitate the visualization process, the activation of words belonging to the frame, and the linking of verbal and visual information in long-term memory. They record this verbal description in the target language using Windows Movie Maker or the record mode of an MP3 player. In this way, they will have a register of their first impressions, and of what they consider to be the prototypical elements of the scene. For example, we use symbolic images (see Figure 1) and ask students to describe the denotative as well as the connotative elements of it. Despite largely sharing common cultural values, students' descriptions vary both in the denotative and connotative aspects.

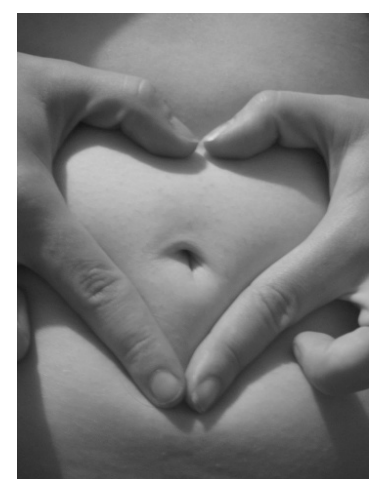

Figure 1. Symbolic photograph

These informal Thinking Aloud Protocols will allow students and researchers to better understand the mental processes involved in the comprehension of audiovisual material and in translation. 


\section{Working with accessible multimedia contents in the translation classroom}

Translating dynamic audiovisual material can be quite a challenge since length and duration restrictions apply not only to tasks such as script translation for captioning/subtitling and dubbing, but also to the translation of web pages and other multimedia documents, where the text must be fitted into limited space and time. However, there is a new context of work for translators in multimedia scenarios which so far has remained a somewhat diffuse and abstract working environment: working with accessibility in mind. Some translation scholars (Orero 2005; Neves 2004 inter alia) have defended the inclusion of accessibility in translation studies as a response to the 'Design for all' programme of the EU. In such a context, e-accessibility is defined as "the integration of all users into the Information Society, i.e. older people, people with disabilities and also people placed in impaired environments" (Europe's Information Society 2002)

Furthermore, multimedia is generally understood as the combination of text, graphics, video, animation, and sound. Therefore, a given piece of multimedia content should be presented in such a way that it complies with the access needs of each media type represented. Since a multi-modal presentation of information can be easier to grasp, multimedia can be useful for many groups of users. For example, audiotracks can be downloaded to be listened to in an offline environment; subtitles can be a quick and economic way to give access to a video content in different languages, and flash presentations can be used to summarize extensive contents in a web.

Consequently, we believe that accessibility can be fostered in different tasks in the translation classroom at various levels. We argue for the enhancement of accessibility in the translation classroom, both to give response to a social need and to bring students closer to a commonplace professional environment. For that reason, we have introduced accessibility proper activities in the scientific and technical translation classroom, as shall be explained below.

\subsection{Accessibility and the $\mathrm{W} 3$ Consortium}

In the context of translating for the Web, according to the W3 Consortium (2005), "web accessibility means that people with disabilities can perceive, understand, navigate, and interact with the Web, and that they can contribute to the Web."

Nevertheless, accessibility is not only about providing information to people with disabilities. The new multimedia formats suggest that information is suited to a variety of users, as regards level of expertise. In such a context, translating with accessibility in mind implies providing alternative formats, and knowing how to respond to the various information needs as 
regards to the level of literacy/expertise. Therefore, web accessibility also benefits other users, including those with low literacy.

One of the aspects dealt with in web translation is the provision of text equivalents for images. Discrete text equivalents - when rendered by players or assistive technologies ${ }^{5}$ to the screen, as speech, or on a dynamic Braille display - allow users to make use of the multimedia object, even if they cannot make use of all of its content. For instance, providing a text equivalent of an image that is part of a link will enable someone with blindness to decide whether to follow the link or not, as stated in the $\mathrm{W} 3 \mathrm{C}$ recommendation (1999) dealing with the accessibility features of the Synchronized Multimedia Language. Following the Guideline 1.1 of the WCAG 2.0, we base our work on the basic rule of providing text alternatives for all non-textual content, providing text for multimedia material, and for audioonly and video-only material.

\subsection{Film Translation: a pedagogical tool for learning the recommenda- tions of the $\mathbf{W} 3$ Consortium}

In the context of audiovisual scenarios, and according to the W3 Consortium, accessibility problems include the lack of captions, transcripts or audio descriptions in digital videos.

Two special equivalents that promote accessibility are captions and auditory descriptions. A caption is a text transcript of spoken words and non-spoken sound effects that provides the same information as a presentation's audio stream and is synchronized with the video track of the presentation. Captions benefit people who are deaf, hard of hearing, or who have auditory learning disabilities or reading speed issues. They also benefit anyone in a setting where audio tracks would cause disturbance, where ambient noise in the audio track or listening environment prevents them from hearing the audio track, or when they have difficulties in understanding spoken language (W3C 1999).

Just as developers are working to enhance the accessibility of multimedia for all users, translators are faced with the new challenge of being aware of the need to provide captions, transcripts and audio descriptions within the multimedia formats they work with.

The recommendations of the W3 Consortium include enhancing accessibility for text, audio and images, since multimedia can combine all of these elements. We propose a progressive introduction of accessibility features in the translation classroom, from text equivalents for images, to definitions of specialized terms for the non expert, or the provision of captions in videos. With this in mind, we try to exploit our material in such a way that students are able to carry out other translation-related tasks such as summarizing translations to fit in voice-over tasks, building up multilingual multimedia glossaries from a video or doing subtitles for accessibility purposes. 


\section{Materials and activities to integrate AVT in the teaching of scientific and technical translation}

Multimedia materials can be used in two different ways in the teaching of scientific and technical translation. They can appear as objects of translation (in localisation, dubbing or subtitling) or as instructional resources when translating a scientific or technical written text.

Illustrations, especially those which fulfil at least one of the functions explained in section 2.2., are particularly useful for instructional purposes and contribute to the subprocesses involved in the learning process, which is facilitated by the inclusion of these types of illustrations as multimedia materials in educational contexts.

In this section, we will use different multimedia texts available at a mouse click, and will show how they can be manipulated and exploited in the scientific and technical classroom. The following set of activities contains different multimedia elements which are supported on the contiguity principle in the text-image interface and highlight the five functions described by Levin (1981). The activities include a series of multimedia elements which focus on terminology, and are aimed at the translation of html, subtitling, audiodescription and voiceover. In the following sections, we will develop some of these activities in more detail and will present a summary chart where activities are ordered according to difficulty.

\subsection{Pre-translation activities and self-evaluation}

The main objective is to introduce students to the terminology of the subject fields being translated, HYDROLOGY AND COASTAL ENGINEERING, and to the methodology proposed in this type of multimedia translation through simple activities which involve pictorial and audio elements:

- $\quad$ transcripting an audio script for knowledge acquisition;

- $\quad$ making a list of key terms from transcript with the aid of a Corpus tool such as WordSmith Tools;

- $\quad$ distinguishing between focalised and topicalised information;

- $\quad$ identifying the functions of images in relation to text (Paivio 1971; 1990);

- $\quad$ summarizing the information for different purposes;

- Gap-fill and multiple-choice activities to deepen terminological/phraseological knowledge in the subject field (Halfbaked software 1997-2006, http://hotpot.uvic.ca).

The self-evaluation feature helps students check the score achieved on their own, so that they can assess the knowledge acquired in the pre-translation stage. Every activity has been designed using HotPotatoes v6 (Half-baked software 1997-2006, http://hotpot.uvic.ca) and they complement each other in providing background knowledge prior to the translation stage. 


\subsubsection{Visualization activity to increase environmental concern}

\section{Activity: Water Campaign I}

The following video has been chosen by the Andalusian Regional Government to illustrate a campaign to save water in domestic use. View the video campana_h2o.mpeg and answer the following questions:

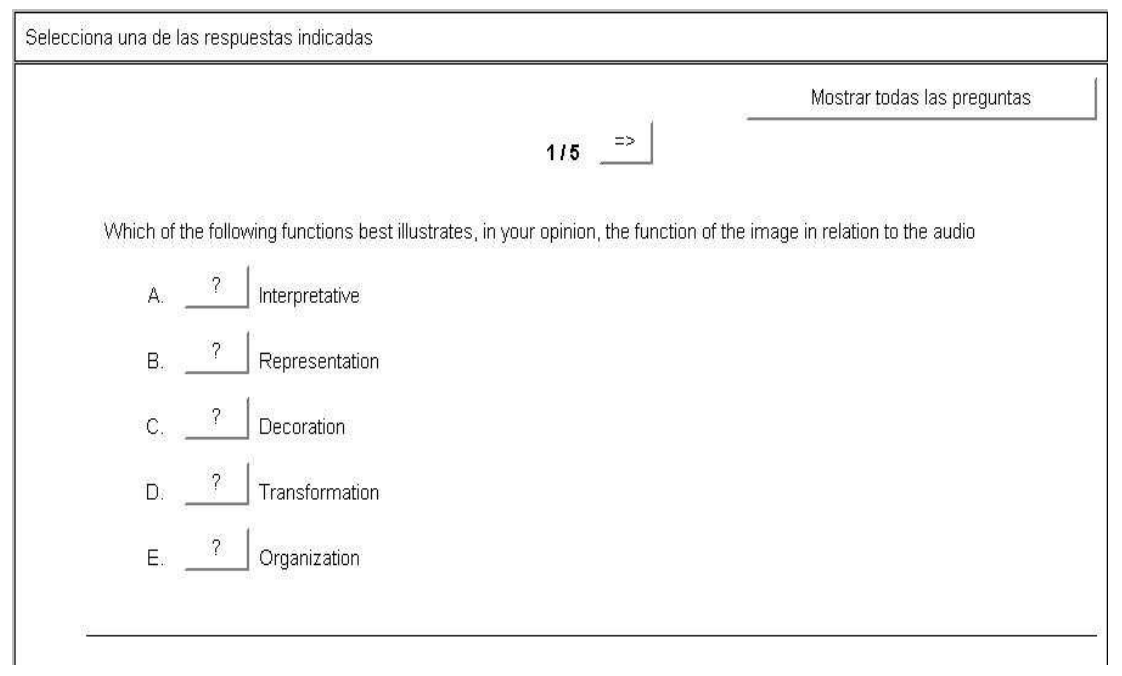

Figure 2: "Multiple choice" Water Campaign Activity I

\subsubsection{Activity to get familiar with TYPES OF WAVES}

\section{Activity: Types of waves I}

In this activity, students hear a scientific narration, and must fill in the missing words in a written version with gaps (Figure 3). Such words are actually terms belonging to the subject field (WAVE TYPOLOGY). This exercise can be presented in the form of a dictation or as a different passage to be completed according to the information offered in the audio. 


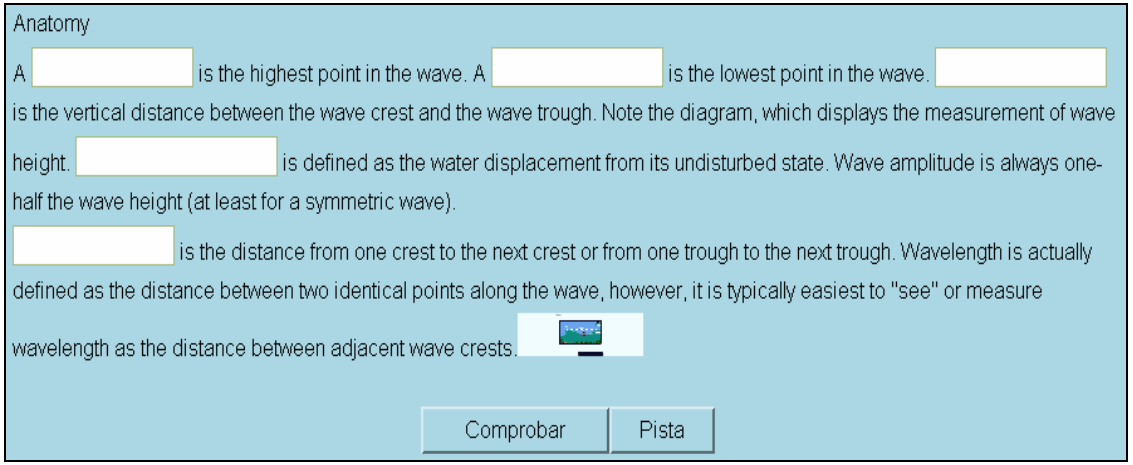

Figure 3: "Gap-fill" activity 1

Next, we propose a multiple-choice exercise. Students are intended to answer the questions by choosing one of the three possible answers according to what is said in the audio, which lasts 2 minutes. They have three minutes in total to complete the exercise.

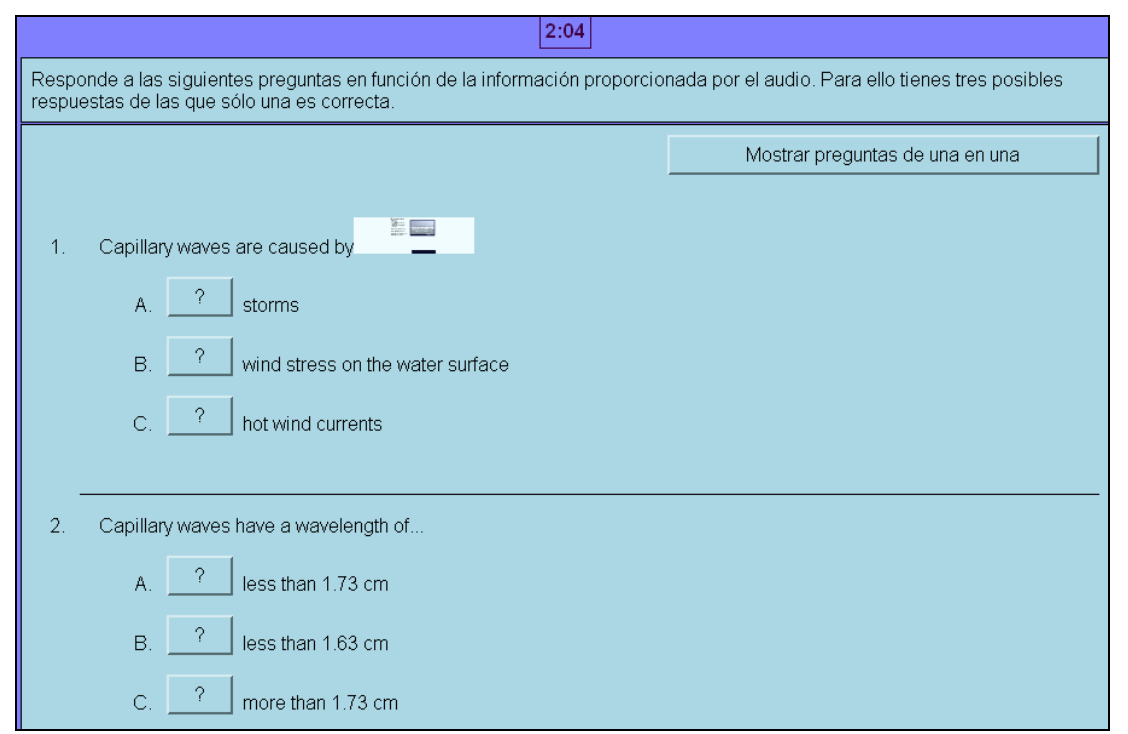

Figure 4: "Multiple-choice" activity 2

The last pre-translation task to get familiar with WAVE TYPOLOGY consists of a matching exercise in which, according to the audio, students must choose one of the items proposed to complete a syntactically and semantically correct sentence. This exercise is also timed since one of the objectives in the pre-translation stage is to help students acquire some knowledge in the field but in stress conditions, in order to simulate a real translation process in which translators must normally learn the basics of a scientific subject to understand what they are supposed to translate. 


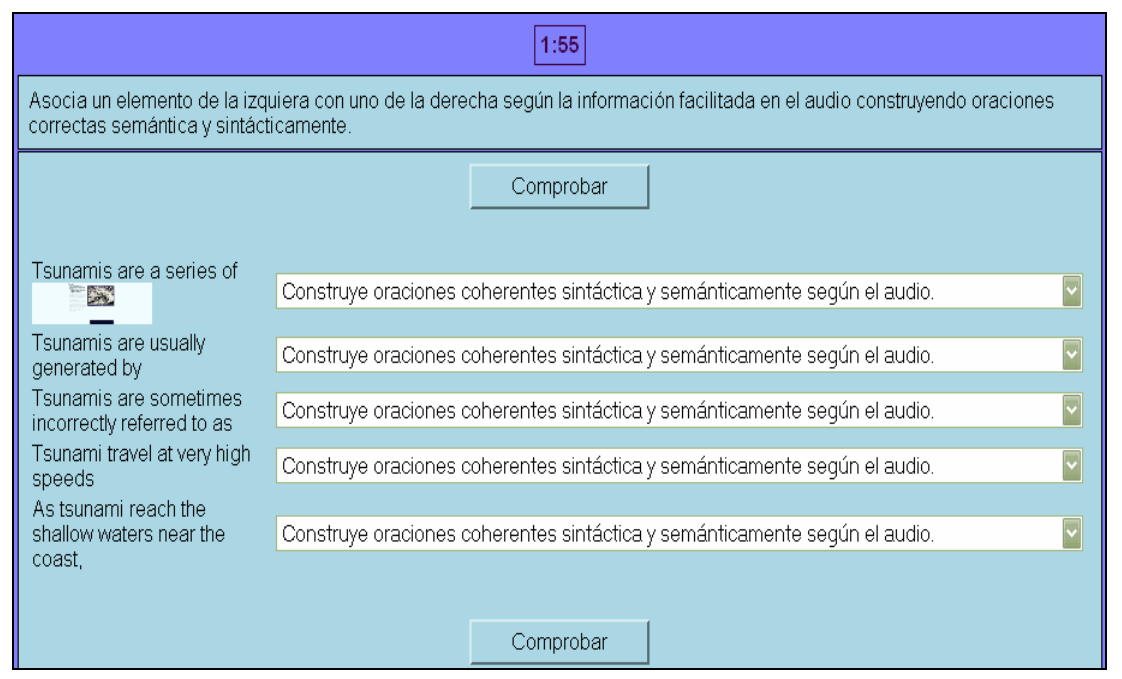

Figure 5: "Complete the sentence" activity 3

\subsection{Translating html documents: a gate to multimedia}

A good way of introducing students to multimedia learning environments is the translation of web pages, which includes:

- $\quad$ translating the complexity of web material including text, images, forms, sounds and such;

- $\quad$ knowing how to assess different text types in the same page;

- $\quad$ becoming acquainted with the multiple formats in a web document;

- becoming aware of the importance of hypertext writing for different users in a way that all text hyperlinks are written so that they make sense when read out of context;

- $\quad$ providing text alternatives for images in an accessible multimedia environment.

Fourth year students enrolled in an optional e-learning course in Localisation and Audiovisual Translation were faced with an assignment consisting in the translation of several web pages for a corporative site. No particular indications with regard to specific tools or formats were given. Of the 82 students enrolled, 52 translated the pages using beginners' CAT tools such as Catscradle, only one used Tag Editor and 6 used an editor such as Textpad or Notepad.

When asked about the reasons that led them to make that choice, most of them agreed that the tools were chosen on the basis of usability, pointing at things like "you don't have to worry about tags".

These data are of course neither conclusive nor exhaustive but give us an idea of the areas of improvement that have to be the focus of AVT teaching. Translating html documents in the translation classroom is a task 
that requires from students a shift from the procedures of other more traditional formats like those of general or literary translation:

- understanding the complexity of web contents defined as the information in a Web page or Web application, including text, images, forms, sounds, and such (W3 Consortium);

- $\quad$ knowing how to assess different text types (legal, technical, marketing) in the same page;

- $\quad$ becoming acquainted with the multiple formats in a web document;

- becoming aware of the importance of hypertext writing for different users in a way that all text hyperlinks are written so that they make sense when read out of context.

\subsection{Subtitling and Audiodescription: interaction of images and text}

\section{Activity: Water Campaign II}

The activities involving the interaction of images and text comprise:

- $\quad$ making specialized films accessible by assessing the audience;

- $\quad$ assessing the needs of the hard of hearing in the AVT classroom; subtitles for the hard of hearing;

- $\quad$ assessing the needs of different age groups. Introducing subtitles for children in documentaries.

In this activity, students will transcribe the audio material of the video presented in 4.1.1. (Water campaign). They can assess their transcription with the following self-evaluation activity. Students should choose the transcript which best fits for subtitling purposes. The transcript reads:

Water is in everything you love

Caring for water// you are caring for what you love

And we will be saving water for a whole year

Andalusian Regional Government

Department of Environment 


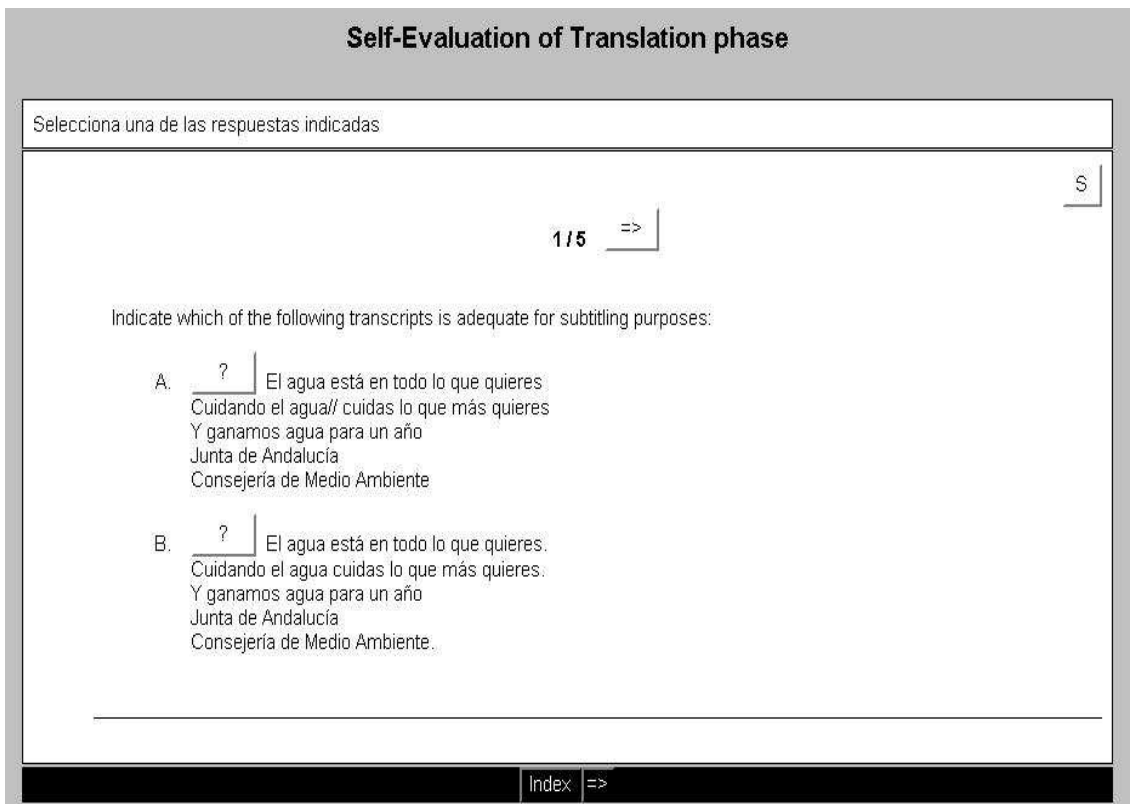

Figure 6: Water Campaign Activity II

Next, they will subtitle the video in English using Subtitle Workshop. To that end, they have to take into account the interaction between images and text, and the time and space constraints imposed on their target text.

Table 3: Subtitling activity with Subtitle Workshop

\begin{tabular}{|l|l|}
\hline \multicolumn{1}{|c|}{ Source Text } & \multicolumn{1}{c|}{$\begin{array}{c}\text { Target Text } \\
\text { (with Subtitle Workshop) }\end{array}$} \\
\hline $\begin{array}{l}\text { El agua está en todo lo que quieres } \\
\text { Cuidando el agua } \\
\text { cuidas lo que más quieres }\end{array}$ & $\begin{array}{l}\text { 00:00:00:00 00:00:00:00 } \\
\text { [Water dripping] } \\
\text { 00:00:00:00 00:00:00:00 } \\
\text { Caring for water, } \\
\text { you are caring for what you love }\end{array}$ \\
$\begin{array}{l}\text { Y ganamos agua para un año } \\
\text { 00:00:00:00 00:00:00:00 } \\
\text { And we will be saving water } \\
\text { for a whole year }\end{array}$ \\
$\begin{array}{l}\text { Junta de Andalucía } \\
\text { Consejería de Medio Ambiente }\end{array}$ \\
\end{tabular}

Then, they will subtitle the video in English using the freeware subtitling application Subtitle Workshop. To that end, they have to take into account the interaction between images and text, and the time and space constraints 
imposed on their target text by Spain's standard conventions with regard to closed captions.

\subsection{Voiceover: audio transcription and script translation}

At this stage, students are asked to carry out some activities on voiceover:

- adapting transcripts to fit the shortened/extended audio duration of the target language;

- $\quad$ translation of scripts/transcripts for voiceover purposes;

- $\quad$ recording voiceover.

Once students have finished the pre-translation stage and thus acquired the basics on WAVE TYPOLOGY they must transcribe the audio in the html files (contained in Flash animations) in the form of a script from which they should produce the Spanish translation. This script may also be used for voiceover purposes in a subsequent recording activity.

\section{Activity: Types of waves II}

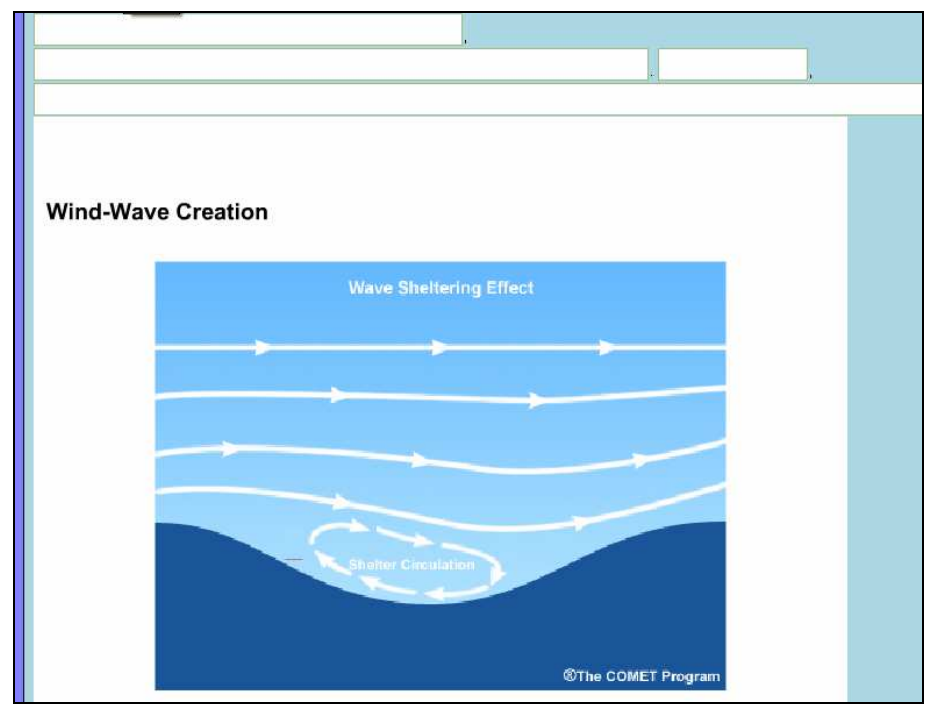

Figure 8: Audio transcription interface

The script should be adequate to the textual conventions commonly used in the Spanish written language and to the accessibility requirements proposed by the W3C, according to which a web page or multimedia resource must include a textual description for every audio or pictorial element (W3C 2000), so that it facilitates the access of prospective users with impaired vision or hearing. In addition to the activities proposed, the possibilities of using multimedia materials in the audiovisual translation classroom are 
endless. For example, the translated script could be narrated again by using recording software such as Windows Movie Maker in order to produce a voiceover product.

\subsection{Summary of tasks carried out in the scientific and technical class- room}

Finally, we propose a chart with the progressive tasks our students are enrolled with, the technical tools needed and the competence they develop.

Table 4: Summary of AVT tasks

\begin{tabular}{|c|c|c|c|}
\hline Students & Tasks & $\begin{array}{c}\text { Technical } \\
\text { tools }\end{array}$ & Competences developed \\
\hline All years & $\begin{array}{l}\text { Transcripting the } \\
\text { video. }\end{array}$ & & \\
\hline $\begin{array}{l}\text { Scientific and } \\
\text { Technical } \\
\text { translation }\left(3^{\text {rd }}\right. \\
\left.\text { and } 4^{\text {th }} \text { years }\right)\end{array}$ & $\begin{array}{l}\text { Extracting key- } \\
\text { words from the } \\
\text { transcript. }\end{array}$ & $\begin{array}{l}\text { Corpus } \\
\text { WordSmith } \\
\text { Tools }\end{array}$ & $\begin{array}{l}\text { Learning to identify key } \\
\text { information. }\end{array}$ \\
\hline $\begin{array}{l}\text { Scientific and } \\
\text { Technical } \\
\text { translation }\left(3^{\text {rd }}\right. \\
\left.\text { and } 4^{\text {th }} \text { years }\right)\end{array}$ & $\begin{array}{l}\text { Compiling a bi- } \\
\text { lingual glossary at } \\
\text { different levels of } \\
\text { expertise. }\end{array}$ & Multiterm & $\begin{array}{l}\text { Focusing on the pragmat- } \\
\text { ics of terminology man- } \\
\text { agement. }\end{array}$ \\
\hline $\begin{array}{l}\text { Scientific and } \\
\text { Technical } \\
\text { translation }\left(3^{\text {rd }}\right. \\
\left.\text { and } 4^{\text {th }} \text { years }\right) \\
\left.\text { AVT ( } 4^{\text {th }} \text { year }\right)\end{array}$ & $\begin{array}{l}\text { Providing audi- } \\
\text { odescription de- } \\
\text { scribing essential } \\
\text { visual elements } \\
\text { for video content. }\end{array}$ & & Describing strategies. \\
\hline $\operatorname{AVT}\left(4^{\text {th }}\right.$ year $)$ & $\begin{array}{l}\text { Interlinguistic } \\
\text { subtitling and } \\
\text { captioning. }\end{array}$ & $\begin{array}{l}\text { Fab Subtitler, } \\
\text { winCaps, Subti- } \\
\text { tle Workshop }\end{array}$ & $\begin{array}{l}\text { Following technical and } \\
\text { format constraints. } \\
\text { Following accessibility } \\
\text { guidelines: Synchronized } \\
\text { transcripts of dialogue and } \\
\text { important sound effects. } \\
\text { Captions provide access to } \\
\text { multimedia for people who } \\
\text { are deaf or hard of hearing. }\end{array}$ \\
\hline $\operatorname{AVT}\left(4^{\text {th }}\right.$ year $)$ & $\begin{array}{l}\text { Dubbing and } \\
\text { voiceover }\end{array}$ & $\begin{array}{l}\text { Windows Mo- } \\
\text { vie Maker }\end{array}$ & $\begin{array}{l}\text { Adapting script to fit ex- } \\
\text { tended audio in the target } \\
\text { language. }\end{array}$ \\
\hline
\end{tabular}




\begin{tabular}{|c|c|c|}
\hline $\operatorname{AVT}\left(4^{\text {th }}\right.$ year $)$ & $\begin{array}{l}\text { Combination of } \\
\text { captions and } \\
\text { audiodescription. }\end{array}$ & $\begin{array}{l}\text { Consider the importance of } \\
\text { the timing of media con- } \\
\text { tents when planning access } \\
\text { features. For example, a } \\
\text { "talking head" video may } \\
\text { need only a stand-alone } \\
\text { transcript of the audio, but } \\
\text { a documentary including } \\
\text { graphics and other impor- } \\
\text { tant visuals may require } \\
\text { captions in order to main- } \\
\text { tain the link between } \\
\text { visuals and narration. } \\
\text { Source: } \\
\text { http://ncam.wgbh.org/salt/ } \\
\text { guidelines/sec5.html }\end{array}$ \\
\hline
\end{tabular}

\section{Conclusions}

In this paper we have shown that it is possible to exploit multimedia documents in the scientific and technical translation classroom, since recent changes and advances in Information Technology have enhanced the role of multimedia in AVT. Our proposal of activities considers multimedia contents from two points of view:

- $\quad$ as pedagogical resources that will enable students to become familiar with the subject field of the source text, and to build a sound foundation for knowledge representation;

- and as objects of translation meeting the requirements of accessibility. The translation of audiovisual documents activates the link between images and text, enables visualization, and triggers creativity.

Therefore, when introducing audiovisual material in the scientific and technical classroom, we provide our students with valuable tools to meet the new challenges of the translation market, increasingly influenced by new audiovisual scenarios.

\section{Bibliography}

Anglin, Gary, Hossein Vaez \& Kathryn Cunningham (2004). "Visual representations and learning: the role of static and animated graphics". Visualization and Learning 33, 865-916.

Asher, James (1982). Learning another Language through actions. CA: Sky Oaks Publications. Barsalou, Lawrence (2003). "Situated simulation in the human conceptual system". Language and Cognitive Processes 18 (5-6), 513-562. 
Europe's Information Society (2002). "Design for All”. http://ec.europa.eu/information_society/ activities/einclusion/policy/accessibility/dfa/index_en.htm. (last visited on 20 November 2007).

Faber, Pamela, Carlos Márquez Linares \& Miguel Vega Expósito (2005). "Framing Terminology: A process-oriented approach". Meta 50 (4). http://www.erudit.org/livre/meta/2005/ 000255co.pdf . (last visited on 20 November 2007).

Faber, Pamela, Prieto, Juan A. León, Pilar and Reimerink, Arianne. (2007). "Linking images and words: the description of specialized concepts". International Journal of Lexicography 20 , 39-65.

Fillmore, Charles (1976). "Frame semantics and the nature of language". Annals of the New York Academy of Sciences: Conference on the Origin and Development of Language and Speech 280, 20-32.

Fillmore, Charles (1985). "Frames and the semantics of understanding". Quaderni di Semantica 6 , 222-253.

González Davies, María (2004). Multiple voices in the Translation Classroom. Amsterdam: John Benjamins.

IMS (2002). "Guidelines for Accessible Delivery of Text, Audio, Images, and Multimedia". IMS Guidelines for developing accessible learning applications. Version 1.0. White Paper. http://ncam.wgbh.org/salt/guidelines/sec5.html. (last visited on 25 March 2006).

Kiraly, Don (2000). A Social Constructivist Approach to Translator Education. Manchester: St. Jerome.

Kussmaul, Paul (2005). “Translation through Visualization”. Meta 50 (2), 378-391.

Levin, Joel (1981). "On the functions of pictures in prose". F. Pirozzolo \& M. Wittrock (eds). Neuropsychological and cognitive processes in reading. New York: Academic Press, 203228.

López Rodríguez, Clara Inés, Bryan Robinson \& María Isabel Tercedor Sánchez (2007). “A learner generated corpus to direct learner centered courses". In M. Thelen \& B. Tomaszczyk (eds). Translation and Meaning Part 7. Masstricht: Zuyd University, Maastricht School of International Communication, Department of Translation and Interpreting, 197-212.

Malena, Anne (2003). "Review on Kiraly's A Social Constructivist Approach to Translator Education; Empowerment from Theory to Practice". Meta 48 (4): 596-597.

Mayer, Richard \& Joan Gallini (1990). "When is an illustration worth ten thousand words?". Journal of Educational Psychology 82 (4), 715-726.

Mayer, Richard \& Richard Anderson (1992). "Animation: Helping Students Build Connections Between Words and Pictures in Multimedia Learning". The instructive 84 (4), 444-452.

Orero, Pilar (2005). "La inclusión de la accesibilidad en comunicación audiovisual dentro de los estudios de traducción audiovisual". Quaderns: revista de traducció 12, 173-185.

Paivio, Antonio (1971). Imagery and Verbal Processes. New York: Holt, Rinehart \& Winston.

Paivio, Antonio (1990). Mental representations: A dual coding approach. New York: Oxford University Press.

Parrish, Pat (1999). "Instructional Illustrations". University Corporation for Atmospheric Research. On line at: http://www.comet.ucar.edu/presentations/illustra/. (last visited on 10 December 2007).

Tercedor Sánchez, María Isabel, Clara Inés López Rodríguez \& Bryan Robinson (2005). "Textual and visual aids for e-learning translation courses" Meta 50 (4). On line at: http://www.erudit.org/livre/meta/2005/000243co.pdf . (last visited on 2 November 2007).

Tercedor Sánchez, María Isabel \& Francisco Abadía Molina (2005). "The role of images in the translation of technical and scientific texts". Meta 50 (4). http://www.erudit.org/ livre/meta/2005/000224co.pdf . (last visited on 22 November 2007).

World Wide Web Consortium (1999). "Accessibility Features of SMIL”. On line at: www.w3.org/TR/SMIL-access. (last visited on 10 December 2007)

World Wide Web Consortium (2000). "Html techniques for web content accessibility guidelines 1.0". http://www.w3.org/TR/WCAG10-HTML-TECHS/\#text-equivs-multimedia. (last visited on 20 November 2007).

World Wide Web Consortium (2002). "Web content accessibility guidelines 2.0 Working draft". On line at: http://www.w3.org/TR/WCAG20/appendixB.html. (last visited on 20 November 2007).

World Wide Web Consortium (2005). "Introduction to web accessibility". http://www.w3.org/WAI /intro/accessibility.php. (last visited on 20 November 2007). 
1 This research is part of the project MarcoCosta: marcos de conocimiento multilingüe en la gestión integrada de zonas costeras (P06-HUM-01489), funded by the Andalusian Regional Government.

2 Languages and the Media, Berlin, 25th-27th October 2006; Audiovisual Media Accessibility for People with Disabilities (AMADIS 2006), Madrid, 11th July 2006 (1st edition) and AMADIS 2007, Granada 20th-22nd June 2007 (2nd edition).

3 These teaching materials have been proposed in an innovation action called Localisation of multimedia texts: creation of teaching resources in the scientific and technical classroom.

4 Asher (1982: 64) claims that optimal learning takes place when students construct a new reality through the direct manipulation of people, places and things.

5 Assistive technology enables people with disabilities to accomplish daily living tasks, assists them in communication, education, work or recreation activities, in essence, helps them achieve greater independence and enhances their quality of life. 